\title{
Inhibition of p38/Mk2 signaling pathway improves the anti-inflammatory effect of WIN55 on mouse experimental colitis
}

\author{
Yu Y Li ${ }^{1}$, Birol Yuece ${ }^{2}$, Hua M Cao ${ }^{1}$, Hong X Lin', Shuai Lv', Jie C Chen', Stephanie Ochs², Andrej Sibaev², \\ Elisabeth Deindl ${ }^{3}$, Claus Schaefer ${ }^{2}$ and Martin Storr ${ }^{2}$
}

P38/Mk2 (mitogen-activated protein kinase (MAPK)-activated protein kinase-2, also known as MAKAP kinase-2) is a member of the mitogen-activated protein kinases (MAPKs) family, and participates in inflammatory responses directly or indirectly. WIN55, 212-2 (WIN55) is a synthetic non-selective agonist of cannabinoid (CB) receptors with remarkable antiinflammatory properties. This study was to explore the roles of WIN55 and p38/Mk2 signaling pathway in dextran sodium sulfate (DSS)-induced mouse colitis and ascertain their anti-inflammatory mechanisms. Colitis was induced in C57BL Mk2 gene homozygous deletion $(M k 2-/-)$ and wild-type mice by replacing the drinking water with $4 \%$ DSS solution for 7 days. DSS-treated mice developed bloody stool, weight loss, and eye-visible multiple bleeding ulcers on colon mucosa. The mRNA expressions levels of TNF- $\alpha$ and IL-6, as well as the protein levels of p38 and its phosphorylated form (p-p38), were upregulated in the colon. The plasma levels of TNF- $\alpha$, IL-6, cytokine-induced neutrophil chemoattractant-1 (CINC-1), monocyte chemoattractant protein-1 (MCP-1), and lung myeloperoxidase (MPO) activities were raised; however, all these changes were less severe in Mk2 - I - mice. After WIN55 intervention, the Mk2 - / - mice recovered faster and better from the induced colitis than their wild-type counterparts. The results indicate that the $M k 2$ homozygous deletion in mice impedes the induction of experimental colitis by DSS, confirming the notion that $\mathrm{p} 38 / \mathrm{Mk} 2$ is involved in this inflammatory response. WIN55 protects mice against DSS-induced colitis, in particular when the p38/Mk2 pathway is obstructed, implying that the activation of CB system, together with blocking of p38/Mk2 pathway, serves as a potential drug target for colitis treatment.

Laboratory Investigation (2013) 93, 322-333; doi:10.1038/labinvest.2012.177; published online 4 February 2013

KEYWORDS: cannabinoids; inflammation; mouse DDS colitis; Mk2; p38 MAP kinases

Inflammatory bowel disease (IBD) is a group of chronic intestinal diseases. Among them, ulcerative colitis (UC) and Crohn's disease $(\mathrm{CD})$ are the most common types ${ }^{1}$ characterized by the overactive immune system and excessive production of inflammatory mediators. The manifestations of IBD include abdominal pain and cramps, weight loss, diarrhea, disrupted digestion, and rectal bleeding, accounting for substantial burden and discomfort in patients' everyday life. ${ }^{2,3}$ Despite the fact that much efforts and resources have been invested into the investigation of IBD, the etiology and pathogenesis of the diseases remain elusive.
Different groups of investigators have discovered that the p38 mitogen-activated protein kinase (MAPK) is a crucial mediator of inflammation in IBD., ${ }^{4,5}$ In patients suffering from IBD, an increased activity of p38 MAPK has been observed, ${ }^{6}$ in both immune and non-immune cells. It has been well established that $\mathrm{p} 38$ MAPK positively regulates the expression of inflammation-related genes including those coding for proinflammatory cytokines, such as tumor necrosis factor- $\alpha$ (TNF- $\alpha$ ), interleukin $1 \beta$ (IL-1 $\beta)$, IL-6, and IL-8 in different cell types, however, especially in monocytes and macrophages. ${ }^{7}$ On the other side, non-immune cells,

\footnotetext{
${ }^{1}$ Department of Pathophysiology, Institute of Digestive Disease, Tongji University School of Medicine, Shanghai, China; ${ }^{2}$ Department of Internal Medicine II, Klinikum Grosshadern, Ludwig Maximilians University, Munich, Germany and ${ }^{3}$ Walter-Brendel-Centre of Exp. Medicine, Ludwig Maximilians University, Munich, Germany Correspondence: Dr/Professor YY Li, Department of Pathophysiology, Institute of Digestive Disease, Tongji University School of Medicine, Si Ping Road 1239, Shanghai 200092, China. E-mail: liyongyu@tongji.edu.cn or Dr/Professor M Storr, Department of Internal Medicine II, Klinikum Grosshadern, Ludwig Maximilians University, Marchioninistrasse 15, Munich 81377, Germany. E-mail: gidoc@gmx.de 
such as human intestinal microvascular endothelial cells, intestinal epithelium, fibroblasts, and myofibroblasts, participate in the pathogenesis of IBD as well, and p38 MAPK affect these cells directly or indirectly. ${ }^{8,9}$ Studies have found that SB203580, an inhibitor of p38 activation, suppressed inflammation in mice with dextran sodium sulfate (DSS)-induced colitis and trinitrobenzene sulfonic acid (TNBS)-treated mice by inhibiting p38 MAPK and RICK/NF- $\kappa \mathrm{B}$ signaling pathways. ${ }^{5,10}$ MAPK-activated protein kinase-2, known as MAKAP kinase-2 or Mk2, is a downstream substrate of $\mathrm{p} 38$, and can impact inflammatory responses by regulating the synthesis and secretion of proinflammatory cytokines and by controlling the migration of macrophages, as shown by several investigations. ${ }^{11-13}$ In a murine gene knockout model, the homozygous deletion of Mk2 led to a drastic reduction of TNF- $\alpha$ in these mice when responding to lipopolysaccharide stimulation. ${ }^{13}$ Furthermore, Mk2 deletion interferes with a variety of inflammatory reactions, which include inflammation in the pancreas, ${ }^{14,15}$ neurons, ${ }^{16}$ and joints. ${ }^{17}$

The role of cannabinoids (CBs) in modulating gastrointestinal (GI) inflammation has attracted much research interest in recent years, ${ }^{18,19}$ and investigators have presented solid evidences of the presence of $\mathrm{CB}$ receptors, including $\mathrm{CB} 1$ and $\mathrm{CB} 2$ receptors in the GI tract. ${ }^{19-22}$ Specifically, the murine model colitis induced by different chemicals is generally more severe in CB1 knockout mice than that in wild-type (WT) mice, and pretreatment of WT mice with CB1 receptor antagonists prompts an upregulated inflammatory response in various models, whereas the administration of $\mathrm{CB} 1$ receptor agonists resulted in reduced inflammatory response. ${ }^{23}$ The current knowledge of CB2 receptor in the GI tract supports its role in modulating intestinal inflammation and limiting visceral sensitivity and pain. ${ }^{24}$ WIN55, 212-2 (WIN55), an aminoalkylindole derivative, is a potent synthetic non-selective agonist of $\mathrm{CB} 1$ and $\mathrm{CB} 2$ receptors, and the studies, both in vivo and in vitro systems, have showed that WIN55 exerts multifacet effects on GI, such as reduction of GI transit, defecation and fluid accumulation in mice or rats, inhibition of pentagastrin-stimulated gastric acid secretion, and stressinduced ulceration in rats. ${ }^{21,25}$ Some data indicate that the activation of $\mathrm{CB}$ receptors mediates the protection in colonic inflammation models, ${ }^{22,26}$ yet it is not fully understood where and how the endocannabinoids function in the protection of GI tract. Hence, more detailed investigation is emphatically justified. In addition, medical practice continually demands more options of beneficial therapy for the patients who suffer from IBD and other GI tract disorders. ${ }^{27}$

In this study, we investigated the characteristics and antiinflammatory effects of WIN55 on DSS-induced colitis using Mk2 homozygously deleted $(M k 2-/-)$ mice to further understand the roles of $\mathrm{p} 38 / \mathrm{Mk} 2$ signal pathway and endocannabinoids in the colitis pathogenesis aiming to identify the interplay between them, and to explore new treatment options for IBD.

\section{MATERIALS AND METHODS \\ Animals}

At least 40 healthy mature C57BL/6J WT mice and same number of $M k 2-/-$ mice weighing 25-30 g, half male and half female, were used in this study. The WT mice were purchased from Charles River (Sulzfeld, Germany) and the Mk2 - I - animals were generated on a C57BL/6J genetic background as described previously. ${ }^{11}$ These mice were kept in-house for 2 weeks before experiments. Before and during the experiments, the animals were housed and maintained under controlled environmental conditions: in plastic sawdust floor cages at constant temperature $\left(22^{\circ} \mathrm{C}\right)$ and a 12:12-h light-dark cycle with free access to standard laboratory chow and tap water. The animal experiments were carried out in accordance with the national and international guidelines as outlined in the Guide for the Care and Use of Laboratory Animals, using the protocols approved by the Government of Bavaria animal use committee.

\section{Induction of Experimental Mouse Colitis and Pharmacological Administration}

Experimental colitis was induced by administrating 4\% DSS (molecular weight $40 \mathrm{kDa}$; Sigma, Deisenhofen, Germany) in drinking water for 7 consecutive days (DSS group), WIN55 (Tocris Bioscience, St Louis, MO, USA; catalog (cat.) no. 1038) was administered by intraperitoneal injection, once per day at $5 \mathrm{mg} / \mathrm{kg}$ body weight during the mouse intake period of DSS (DSS + WIN group). For control experiments, mouse tissues and blood samples were analyzed from animals of (1) control group: animals drinking normal water and receiving intraperitoneal injection of $0.9 \% \mathrm{NaCl}$ (normal saline solution, NS) or the WIN55 solvent (Tocrisolve 100; cat. no. 1684); and (2) sole WIN55 group: animals drinking normal water and receiving WIN55 intraperitoneally in the same manner as that of the experimental groups. Thus, totally eight different animal groups with at least eight mice in each group were generated using the C57BL WT and Mk2-Imice.

During the 7 days of colitis induction, the weight, physical condition, stool consistency, and the presence of gross and occult blood in excreta and at the anus of the mice were examined and documented daily (Haemocare, Care Diagnostics, Vörde, Germany). At the end of this 7-day period, all the animals were killed by decapitation under isoflurane anesthesia, and blood specimens were collected and plasma samples were prepared from blood specimens by centrifugation at $12000 \mathrm{~g}$ for $10 \mathrm{~min}$ at $4{ }^{\circ} \mathrm{C}$, and stored at $-80^{\circ} \mathrm{C}$ until further investigations. The colon (starting from $0.5 \mathrm{~cm}$ above the anus to the top of the cecum), and lungs of mice that were killed were carefully dissected, removed, and weighted. To evaluate the injury, colon segments were opened longitudinally, gently cleared of stool, rinsed with normal 
saline, and put on a Whatmann paper for length measurement as an indirect marker of inflammation. The detached colon was then divided into several portions, and one of them was fixed in 10\% neutrally buffered formalin immediately, whereas others were shock-frozen in liquid nitrogen and stored at $-80^{\circ} \mathrm{C}$ until further investigations.

\section{Disease Activity Index}

The colitis disease activity index (DAI) was assessed by an experienced pathologist blinded to the project, by using the evaluation system of Cooper et al ${ }^{28}$ and Hartmann et al: ${ }^{29}$ (i) body weight loss (no weight loss was scored as 0 points, weight loss of $1-5 \%$ as 1 point, $5-10 \%$ as 2 points, $10-20 \%$ as 3 points, and more than $20 \%$ as 4 points); (ii) stool consistency ( 0 point was given for well-formed pellets, 2 points for pasty and semiformed stools that did not stick to the anus, and 4 points for liquid stools that remained adhesive to the anus); and (iii) bleeding (0 point was given for negative stool hemoccult test, 2 points were given for positive hemoccult test, 4 points for gross bleeding from the rectum). These scores were summed up and divided by 3 , resulting in a total clinical DAI ranging from 0 (healthy) to 4 (maximal score for the DSS-induced colitis).

\section{Evaluation of Histological Changes and Inflammatory Cell Infiltration in Colon}

The colon portions fixed in 10\% neutral-buffered formalin as described above were freeze-sliced and paraffin-embedded, and thereafter cut on a Leica RM2126 microtome (Leica, Shanghai, China). Tissue sections $(5 \mu \mathrm{m})$ were stained with hematoxylin and eosin (HE). Five sections at $50 \mu \mathrm{m}$ apart per colon sample were evaluated and repeated in three mice per group in a blinded manner, and scored according to the method of Siegmund et al: ${ }^{30}$ (i) cell infiltration of inflammatory cells $(0$ point for zero or rare inflammatory cells in the lamina propria, 1 for increased numbers of inflammatory cells, including neutrophils in the lamina propria, 2 for confluence of inflammatory cells, extending into the submucosa, and 3 for transmural extension of the inflammatory cell infiltrate); and (ii) epithelial damage (0 point for the absence of mucosal damage, 1 for discrete focal epithelial lesions, 2 for mucosal erosion/ulceration, and 3 for extensive mucosal damage and/or extension through deeper structures of the bowel wall). The two subscores were summed up and the combined histological score ranged from 0 (no changes) to 6 (highest score with extensive cell infiltration and tissue damage).

To define the inflammatory cells involved in the pathogenesis of DSS-induced mouse colitis and to determine the effect of $M k 2-/-$ and WIN55 treatment, the numbers of macrophages, neutrophils, and eosinophils in colon tissues were counted. In brief, tissue sections were stained with $\mathrm{H}$ and $\mathrm{E}(0.5 \%$ and $0.5 \%)$ for eosinophils counting; for macrophages and neutrophils, the tissue sections were immunostained with antibodies recognizing mouse CD68
(Abcam, Cambridge, MA, USA; cat. no. ab125212) or MPO (Biosynthesis Biotechnology Co. Ltd., Beijing, China; cat. no. bs-1061R) in a 1:200 dilution and incubated overnight at $4{ }^{\circ} \mathrm{C}$. Thereafter, tissue sections were incubated with biotinlabeled goat anti-rabbit IgG working fluid (Biosynthesis Biotechnology, Beijing, China; cat. no. SP0023) at $37^{\circ} \mathrm{C}$ for $15 \mathrm{~min}$, followed by incubation with an HRP-labeled streptavidin working solution at $37^{\circ} \mathrm{C}$ for $15 \mathrm{~min}$. Finally, the slides were $\mathrm{DAB}$ stained and nuclear re-stained with hematoxylin. The tissue sections for the negative control were processed through the identical steps, but the primary antibody was replaced by PBS. All slides were visualized and analyzed on a Nikon ECLIPSE Ti microscope employing an NIS-Elements Image Analysis System (Nikon Corporation, Tokyo, Japan). Cells in colon samples of three mice per group were counted in at least three high-power fields (HPF, original magnification, $\times 400$ ) randomly selected in each slide. Results were averaged and expressed as cell number per HPF.

\section{Examination of p38 MAPK Expression by Immunohistochemistry}

The expression and localization of p38 and p-p38 in the colon of mice were determined by immunohistochemistry. The colon portion fixed in $10 \%$ neutral-buffered formalin was freeze-sliced and paraffin-embedded as described above, and the sections $(5 \mu \mathrm{m})$ were de-paraffinized and rehydrated, followed by $3 \%$ peroxide-methanol soaking at room temperature for endogenous peroxidase ablation. After blocking with normal goat serum, the slides were incubated overnight at $4{ }^{\circ} \mathrm{C}$ in a humidified chamber with the anti-p38 $\alpha$ (1:25 dilution) or anti-p-p38 $\alpha$ (1:50 dilution) rabbit polyclonal antibody (Santa Cruz Biotechnology, Santa Cruz, CA, USA; cat. nos. SC-728 and SC-101758, respectively). Biotin-labeled goat anti-rabbit IgG working fluid $50 \mu \mathrm{l}$ (Beijing Biosynthesis Biotechnology, Beijing, China; cat. no.: SP0023) was applied onto each slide and incubated at $37^{\circ} \mathrm{C}$ for $15 \mathrm{~min}$, followed by incubation with an HRP-labeled streptavidin working solution at $37^{\circ} \mathrm{C}$ for $15 \mathrm{~min}$. The slides were subsequently DAB stained (DAB Staining Kit; Wuhan Boster Biological Technology, Wuhan, China; cat. no. AR1022) followed by nuclear re-staining with hematoxylin. Finally, the slides were dehydrated, mounted with neutral gums, and cleared for subsequent examination. The specimens of the negative control group were processed with the same steps, but the primary antibody was replaced by PBS (pH 7.4). Positive signals (brown dyeing) in five sections at least $50 \mu \mathrm{m}$ apart per colon sample were evaluated by using digital Motic Med 6.0 image analysis system (Motic, Wetzlar, Germany).

\section{Quantification of Cytokine and Chemokine mRNA Expression in Colon Tissues by qRT-PCR}

To determine the mRNA expression of different cytokines (IL-6, IL-10, and TNF- $\alpha$ ) and chemokines (cytokine-induced 
neutrophil chemoattractant-1 (CINC-1), monocyte chemoattractant protein-1 (MCP-1), and cyclooxygenase-2 $($ Cox-2)) in the mouse colonic tissue, quantitative real-time reverse-transcription polymerase chain reaction (qRT-PCR) was performed. A colon specimen $4 \mathrm{~cm}$ proximal to the anus from an animal that was killed was excised, homogenized in guandinium buffer $(25 \mathrm{mM}$ sodium citrate tribasic salt dehydrate, $4 \mathrm{M}$ guanidine thiocyanate, $0.5 \% \mathrm{~N}$-lauroylsarcosine, $0.15 \mathrm{M}$ sodium chloride, $0.1 \mathrm{M}$ 2-mercaptoethanol, $\mathrm{pH}$ 7.0), and total RNA extraction was performed according to a protocol described by Chomczynski and Sacchi. ${ }^{31}$ DNasetreated total RNA $(1 \mu \mathrm{g})$ from every RNA preparation was reverse-transcribed using random nonamers and a First Strand cDNA Synthesis Kit for RT-PCR (Roche, Mannheim, Germany; cat. no. 11483188001).

qRT-PCR reactions were performed with a Light Cycler 1.5 (Roche) in a reaction volume of $10 \mu \mathrm{l}$ using a LightCycler FastStart DNA Master ${ }^{\text {plus }}$ SYBR Green I Kit (Roche; cat. no. 04957164702) and 50 pmol of each primers (see below). After initial denaturation for $10 \mathrm{~min}$ at $95^{\circ} \mathrm{C}, 40$ cycles of amplification were performed: denaturation at $95^{\circ} \mathrm{C}$ for $10 \mathrm{~s}$; annealing at $58^{\circ} \mathrm{C}(\mathrm{IL}-6)$ or $56^{\circ} \mathrm{C}(\mathrm{Cox}-2)$ or $60^{\circ} \mathrm{C}(\mathrm{TNF}-\alpha)$ or $66^{\circ} \mathrm{C}$ (IL-10) or $57^{\circ} \mathrm{C}$ (CINC-1) or $64^{\circ} \mathrm{C}$ (MCP-1 and $18 \mathrm{~S}$ rRNA) for $5 \mathrm{~s}$; and extension at $72^{\circ} \mathrm{C}$ for $15 \mathrm{~s}$. At least two independent qRT-PCR reactions were performed on each template of at least five mice per group. The expression level of each transcript within the different samples was quantified as the relative value against $18 \mathrm{~S}$ rRNA expression level according to the protocols of Roche.

The following primers were used in qRT-PCR reactions, and were purchased from Eurofins MWG Operon (Ebersberg, Germany) - 18 S rRNA: sense, 5'-GGACAGGATTGACA GATTGATAG-3'; antisense, 5'-CTCGTTCGTTATCGGAATT AAC-3'; IL-6: sense, 5'-CAACGATGATGCACTTGC-3'; antisense, 5'-GTACTCCAGGTAGCTATG-3'; IL-10: sense, 5'-CA GGCAGAGAAGCATGGC-3'; antisense, $5^{\prime}$-TGCTCCACT GCCTTGCTC-3'; TNF- $\alpha$ : sense, 5'-GCAGCTGGAGTGGC TGAG-3'; antisense, $5^{\prime}$-GGTGAGGAGCACGTAGTC-3'; Cox2: sense, 5'-GAGTCATTCACCAGACAG-3'; antisense, 5'-GA AGCGTTTGCGGTACTC-3'; MCP-1: sense, $5^{\prime}$-CTCAAGAGA GAGGTCTGTGCTG-3'; antisense, 5'-GTAGTGGATGCATTA GCTTCAG-3'; CINC-1: sense, 5'-GTCATAGCCACACTC AAG-3'; antisense, 5'-CCATCAGAGCAGTCTGTC-3'

\section{Determination of Cytokine and Chemokine in Mouse Plasma by ELISA}

The plasma levels of cytokines and chemokines were determined using commercially available mouse-specific enzyme-linked immunosorbent assay (ELISA) kits for TNF- $\alpha$, IL- 6 , CINC-1, and MCP-1 (R\&D Systems, Minneapolis, MN, USA; cat. nos. MTA00, M6000B, MKC00B, MJE00, respectively) based on the manufacturer-recommended protocols. Each sample was measured in duplicate using a microplate reader, and the data were expressed as $\mathrm{pg} / \mathrm{ml}$ plasma or percentage of the control.

\section{Quantification of Mouse Lung MPO Activity}

MPO activity in the mouse lung tissue was measured as described previously. ${ }^{13}$ Briefly, tissue samples were homogenized using an Elmer Potter homogenizer at 2400 r.p.m. An aliquot of this homogenate was taken for protein determination using the Bio-Rad protein assay kit, whereas the rest was centrifuged at $10000 \mathrm{~g}$ at $4{ }^{\circ} \mathrm{C}$ for $10 \mathrm{~min}$. Each pellet was re-suspended in $0.5 \mathrm{ml}$ extraction buffer, snap-frozen, and thawed four times. Samples were subsequently sonicated and centrifuged. The supernatant was used for MPO measurement, and the activity was calculated from the measured absorbance slope and expressed as milliunits per milligram of wet weight of lung tissue, or presented as percentage of control.

\section{Statistical Analysis}

The data are expressed as mean values \pm s.e.m. Values were obtained from multiple determinations in four or more separate experiments with 2-3 animals per group. All data were analyzed by using one-way ANOVA followed by Tukey's multiple comparison with SPSS 13.0 software (SPSS, Shanghai, China). Values of $P<0.05$ were considered statistically significant.

\section{RESULTS}

Mk2 Deficiency and WIN55 Administration Improve DAI and Colon Length in Mice with DDS-induced Colitis

After intake of DSS in drinking water, WT and Mk2-deficient mice developed severe colitis, and suffered weight loss and bloody stools, which typically started at days 3 and 4 and continued to the end of experimental period (day 7). As shown in Figure 1, high scores of DAI for colonic specimens were found in WT and Mk2 - / - mice. Furthermore, these mice suffered from a shortened colon. Although $M k 2-/-$ genotype did not prevent the pathological changes of colitis , both the DAI and the colon shortening were ameliorated to certain extent. WIN55 significantly attenuated the magnitude of DSS-induced DAI and colon shortening in both types of mice, but a more evident effect on DAI was noticed in the Mk2 - I - mice, which even showed significant values when compared with the WT DSS- and WIN55-treated group (Figures $1 \mathrm{a}$ and $\mathrm{b} ; P<0.05$ ). In the control groups, in which no animal was given DSS, mice developed neither colon-local nor systemic inflammatory responses, regardless of solvent or WIN55 administration.

\section{Mk2 Deficiency and WIN55 Administration Improve Histological Changes in the Colon of Mice with DSS-Induced Colitis}

The results of histological examinations demonstrated no signs of colitis in $M k 2-I-$ or WT mice, which exclusively received WIN55 or drug solvent. Treatment of WT mice with DSS induced an obvious colitis with multiple erosive lesions and dropouts of entire crypts in the colon, as well as a marked infiltration of inflammatory cells, especially 
neutrophil granulocytes and lymphocytes, into the colonic submucosa (Figure $2 \mathrm{aB}$, labeled with asterisk $\left(^{*}\right)$ ); hence, a higher histological score was presented when compared with the WT mice in the control group or in the DSS + WIN55 group $(P<0.05)$ (Figure $2 \mathrm{~b}$ ). In contrast, $M k 2-/-$ mice with DSS intake manifested much milder inflammatory responses: light edema, fewer lesions, and modest filtration, justifying lower histological score (Figures 2aE) and b). Treating $M k 2-I-$ mice additionally with WIN55 significantly reduced the DSS-induced mucosal injury, edema, and infiltration of inflammatory cells, and decreased the histological scores of the tissues, showing significant values even when compared with DSS-induced colitis and WIN55treated WT mice (Figures $2 \mathrm{aC}, \mathrm{F}$ and $\mathrm{b}$ ).

\section{Mk2 Deficiency and WIN55 Administration Reduce Inflammatory Cell Infiltration in the Colon of Mice with DSS-Induced Colitis}

The numbers of macrophages, neutrophils, and eosinophils in colon tissues of WT and Mk2 - / - mice treated with DSS, DSS and WIN55, WIN 55 alone, or untreated were counted and representative pictures are shown in Figures 3a-c. CD68
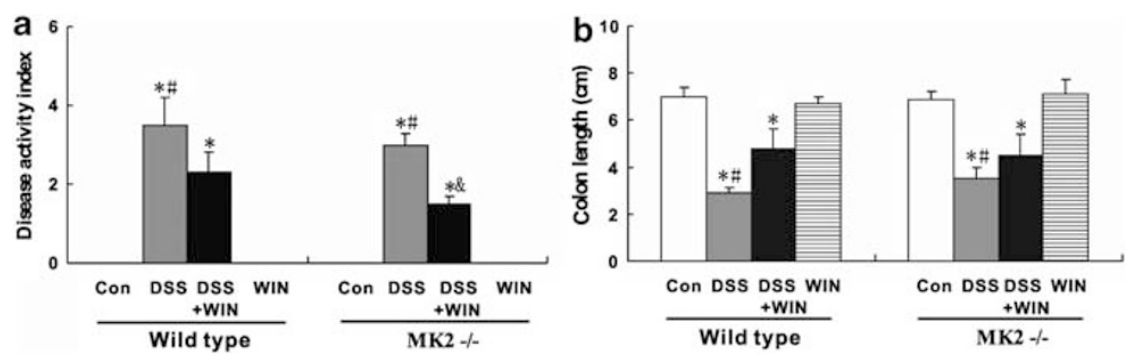

Figure 1 Disease activity index (DAI) and colon length in mice with dextran sodium sulfate (DSS)-induced colitis. Colitis was induced in wild type (WT) and Mk2 - / - mice by oral intake of 4\% DSS for 7 days. Bar graphs representing DAl (a) or colon length (b) in control (Con) animals (white bars), DSStreated animals (gray bars), DSS- and WIN-treated animal (black bars), and single WIN-treated animals (ruled bars). The treatment in every group was: Con: control group in which mice drank water; DSS: the group in which mice drank 4\% DSS solution; DSS + WIN: the group in which mice drank $4 \%$ DSS solution and received WIN55, 212-2 (WIN55) intraperitoneally (i.p.); WIN: the group in which mice drank water and received WIN55 i.p. DAI was assessed according to the system of Cooper et $a^{28}$ and Hartmann et al. ${ }^{29}$ and the total score drifts from 0 (healthy) to 4 (maximal activity of colitis) described in the Materials and Methods section. Colon length $(\mathrm{cm})$ starts from $0.5 \mathrm{~cm}$ above the anus to the top of the cecum. Data are shown as means \pm s.e. ( $n=6-8$ per group, one-way analysis of variance (ANOVA), Tukey's multiple comparison).* $P<0.05$ when compared with the Con or WIN group; ${ }^{\#} P<0.05$ when compared with the DSS + WIN group; ${ }^{~} P<0.05$ when compared with the values of WT mice in the identically treated groups. Mk2, mitogen-activated protein kinase (MAPK)-activated protein kinase-2, also known as MAKAP kinase-2.

a
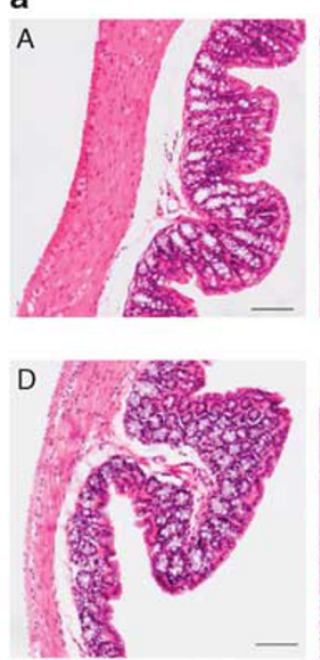
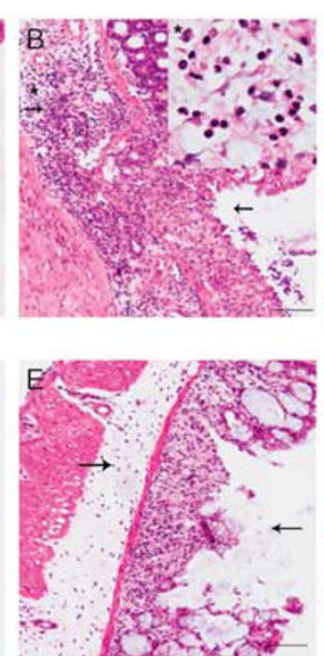
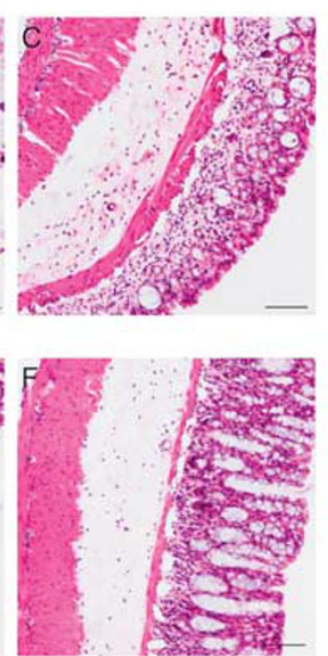

b

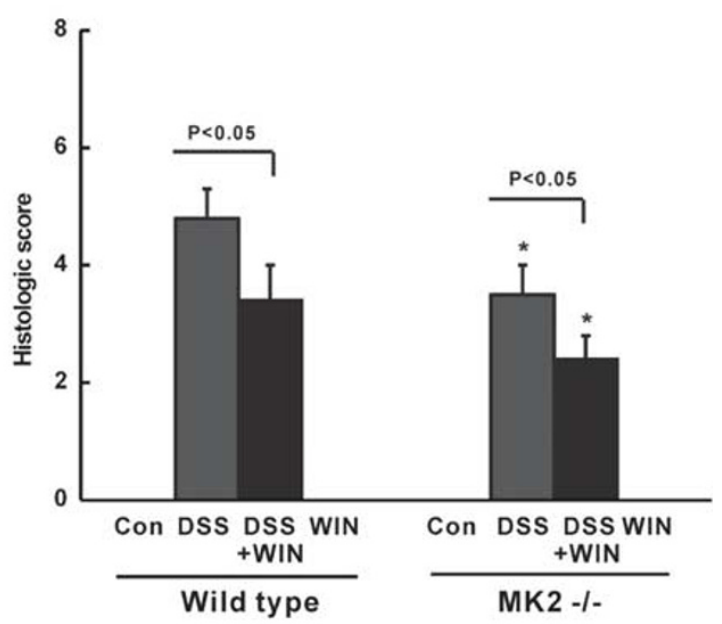

Figure 2 Histological changes in colonic specimens of mice with dextran sodium sulfate (DSS)-induced colitis. (a) Hematoxylin and eosin staining of colonic tissue sections from wild-type (upper panel) and $M k 2-/-$ mice (lower panel). Wild-type mice, upper panel: control (Con) group (A), DSS group (B), and DSS + WIN group (C); Mk2 - / - mice: control group (D), DSS group (E), and DSS + WIN group (F). (original magnification, $\times 100$; scale bar $=50 \mu \mathrm{m}$ ). The arrows point to crypt loss and inflammatory cell infiltration. The inset (original magnification, $\times 400)$ in (B) shows inflammatory cells, especially neutrophils $(*)$. (b) Bar graphs representing the histological score of colon tissue samples isolated from wild-type or Mk2 - / - mice of Con, DSS-, and DSS and WIN 55-treated mice or from mice treated with WIN55, 212-2 (WIN55) alone. Data represent means \pm s.e. ( $n=6-8$ per group, oneway analysis of variance (ANOVA), Tukey's multiple comparison). ${ }^{*} P<0.05$ when compared with the values of wild-type mice in the identically treated groups. Mk2, mitogen-activated protein kinase-activated protein kinase-2, also known as MAKAP kinase-2. 
and MPO staining clearly showed the presence of macrophages and neutrophils (stained in brown) infiltrated in the mucosal and submucosal layers of the colon tissues (Figures $3 \mathrm{a}$ and $\mathrm{b}$ ), and eosinophils with red cytoplasm and blue nucleus mainly located in the submucosa (Figure 3c). The quantification revealed significantly increased numbers of macrophages, neutrophils, and eosinophils in DSS-treated WT mice when compared with DSS-treated $M k 2-/-$ mice $(P<0.05)$. The administration of WIN55 significantly attenuated the DSS-induced changes of inflammatory cells in WT animals $(P<0.05$ for eosinophils, and $P<0.01$ for macrophages and neutrophils); however, it exhibited small effect on $M k 2-/-$ animals $(P>0.05)$. These outcomes confirmed that $M k 2$ deficiency and CB receptor activation had forwarded synergistic protection against deleterious effects of DSS-induced mouse colitis.

\section{Mk2 Deficiency and WIN55 Administration Inhibit p38 MAPK Expression in the Colon of Mice with DSS Colitis}

As shown in Figures 4a-d, p38 and its p-p38 were expressed slightly in the mucosa epithelium and submucosa of the colon tissues in the control groups of both WT and Mk2 - / - mice. Treatment with DSS significantly enhanced their expressions, especially p-p38 expression, and the strong positive signs with brown dyeing were mainly located in inflammatory cells in the colonic submucosal plexus in the both kinds of mice. It is of particular importance that mouse Mk2 homozygous deletion phenotype can alleviate the DSSinduced enhancement of p38 and p-p38 expression $(P<0.01)$, and WIN55 furthers this effect, especially by inhibiting p-p38 expression $(P<0.01)$ (Figures $4 \mathrm{e}$ and $\mathrm{f}$ ).

\section{Mk2 Deficiency and WIN55 Administration Inhibit mRNA Expression of Proinflammatory Cytokines and Chemokines in the Colon of Mice with DSS-induced Colitis}

Cytokine profile is the decisive parameter of any inflammatory process, and cytokine synthesis is regulated by p38/Mk2 signaling pathways. Hence, we examined the mRNA expression level of TNF- $\alpha$, IL-6, IL-10, and Cox-2 in the colonic tissues of mice with DSS-induced colitis using qRT-PCR. The results showed that the mRNA expressions of TNF- $\alpha$, IL-6, IL-10, and Cox- 2 were upregulated significantly $(P<0.01$ or $P<0.05)$ when mice were challenged with DSS (Figures $5 \mathrm{a}-\mathrm{d}$ ). Interestingly, homozygous deletion of $M k 2$ gene attenuated the increased expressions of all the four parameters $(P<0.01$ or $P<0.05)$, and the effects were even strengthened by WIN55 with regard to the expression of TNF- $\alpha$ and Cox-2 $(P<0.05)$ (Figures $5 \mathrm{a}$ and $\mathrm{d})$. In the colon tissues from WT mice, WIN55 downregulated mRNA levels of cytokines, but a significant effect was found only for IL-10 expression (Figure $5 \mathrm{c} ; P<0.05$ ), not for TNF- $\alpha$, IL- 6 , and Cox-2 $(P>0.05)$ (Figures 5a, b, and d).

As shown in Figures $5 \mathrm{e}$ and $\mathrm{f}$, the mRNA expression level of leukocyte chemoattractants, CINC-1 and MCP-1, were also increased significantly in the colon tissues of DSS-treated WT mice $(P<0.01$ vs normal control), and homozygous deletion of $\mathrm{Mk} 2$ gene attenuated their increase significantly $(P<0.01)$. WIN55 downregulated mRNA levels of both chemokines, especially in the colon tissues of WT mice (Figures $5 \mathrm{e}$ and $\mathrm{f} ; \mathrm{P}<0.01$ ).

\section{Mk2 Deficiency and WIN55 Administration Attenuate the Increase of Proinflammatory Cytokines and Chemokines in the Plasma of Mice with DSS-induced Colitis}

To assess the protein levels of TNF- $\alpha$, IL- 6 in mouse plasma, ELISA assay was performed in both $M k 2-/-$ and WT mice. As shown in Figures $6 a$ and $b$, the levels of TNF- $\alpha$ and IL-6 markedly increased after the DSS challenge $(P<0.05$ or $P<0.01)$ in WT animals. In $M k 2-I-$ mice, plasma level increase of both cytokines was less severe, and IL-6 showed even significant reduced values when compared with values of DSS-treated WT mice $(P<0.05)$. Concomitant treatment of mice with WIN55 reduced plasma levels of TNF- $\alpha$ and IL6 in WT and Mk2 - / - mice, a trend that had been observed on mRNA level, too. DSS treatment increased plasma levels of the chemoattractants CINC-1 and MCP-1, as well, however, to a much lesser extent in $M k 2-/-$ mice (Figures $6 \mathrm{c}$ and d). WIN55 supplementation partly attenuated the escalation of CINC-1 and MCP-1 plasma levels, and the effects were even more obvious in $M k 2-/-$ mice. Treatment with solvent or WIN55 alone had no obvious effect on these chemokines. Thus, the results evidently demonstrate that the increased plasma levels of proinflammatory cytokines and chemokines in mice with experimental colitis induced by DSS had been partly reversed by Mk2 deficiency and by the activation of CB receptors.

\section{Mk2 Deficiency and WIN55 Administration Decrease Lung MPO Activity in Mice with DSS-Induced Colitis}

To further evaluate the systemic inflammation in the mouse acute colitis model, we assessed MPO activation, a marker for neutrophil infiltration, in the lung tissue of WT and Mk2 - I - mice after DSS challenge. In WT mice, DSS intake induced a significant increase of MPO activity (12.5-fold compared with control, $P<0.01$ ) (Figure7). In contrast, the DSS intake only meekly increased MPO activity in $M k 2-/$ mice (6-fold compared with control, $P<0.01$ ) (Figure 7). Treatment of mice with WIN55 supplementation significantly reduced the lung MPO activity in both kinds of mice with a reduction about $25 \%$ in WT DSS-treated mice and $40 \%$ in $M k 2-/$ - DSS-treated mice $(P<0.05)$.

\section{DISCUSSION}

DSS-induced colitis in mice is characterized by epithelial damage and robust inflammatory responses in the colon, and this experimentally induced colitis is commonly used as a model system to evaluate the efficacy of new drugs for IBD. ${ }^{32,33}$ In this report, we evaluated the impact of $M k 2$ 

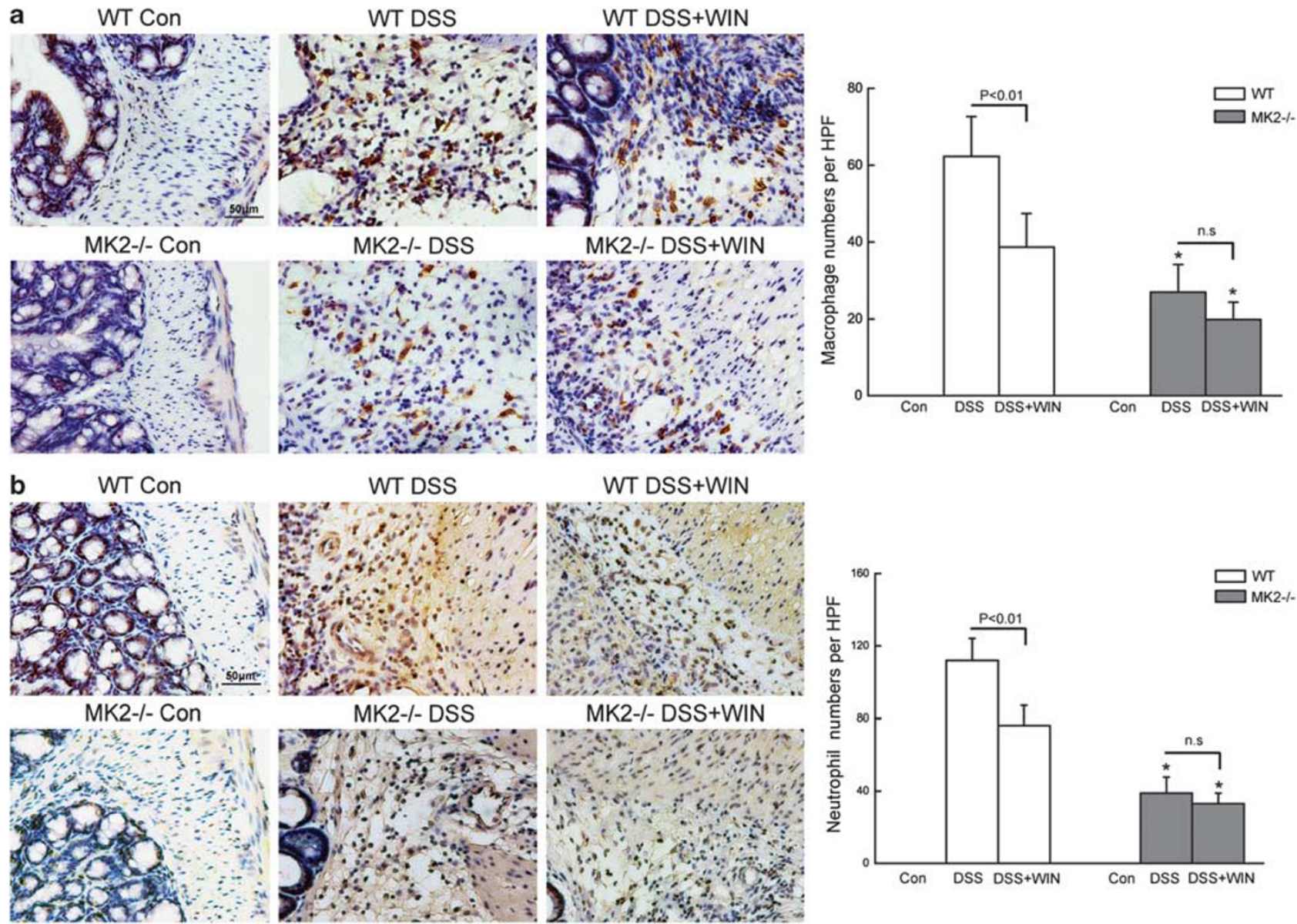

MK2-/- DSS+WIN
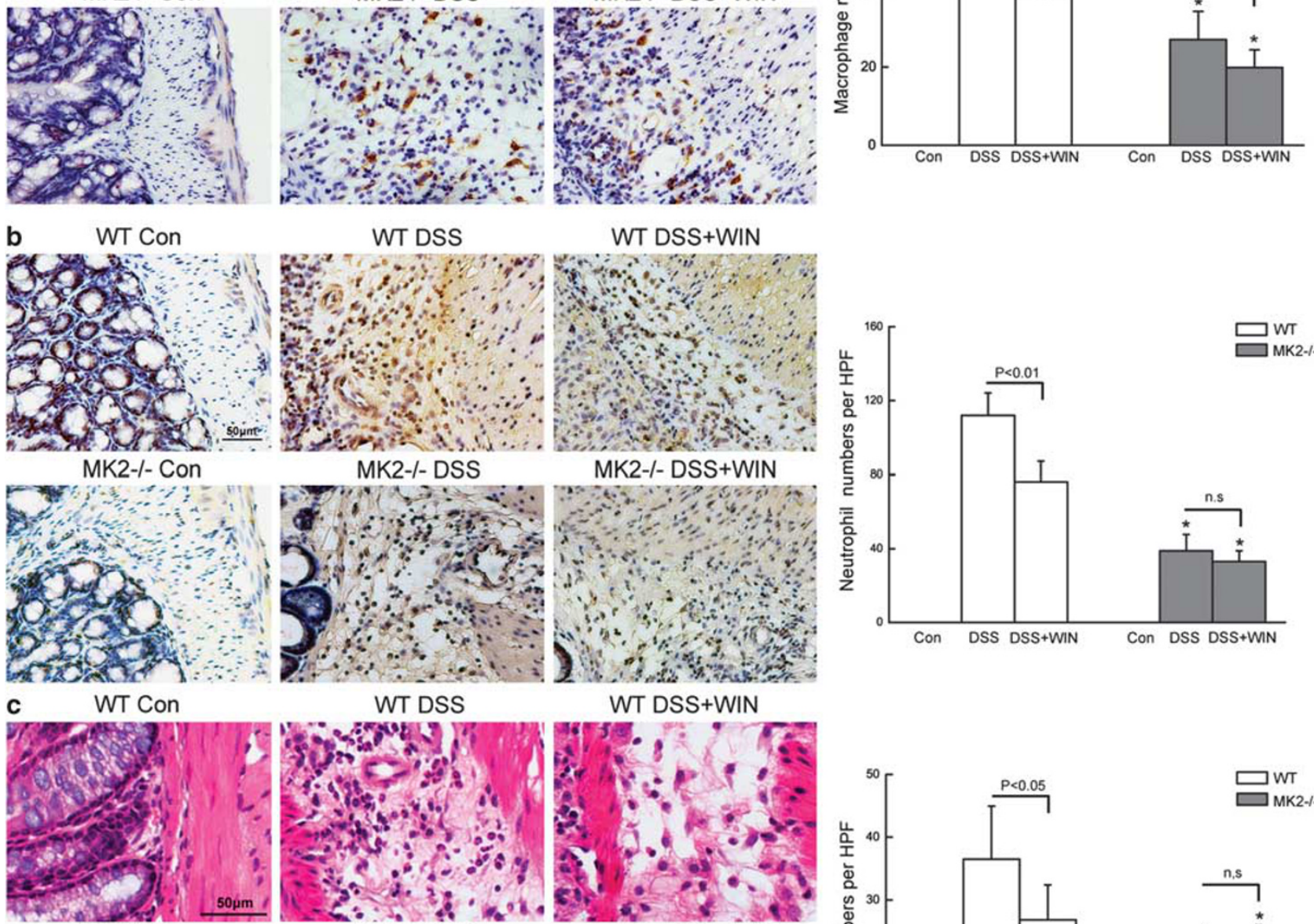

MK2-/- Con
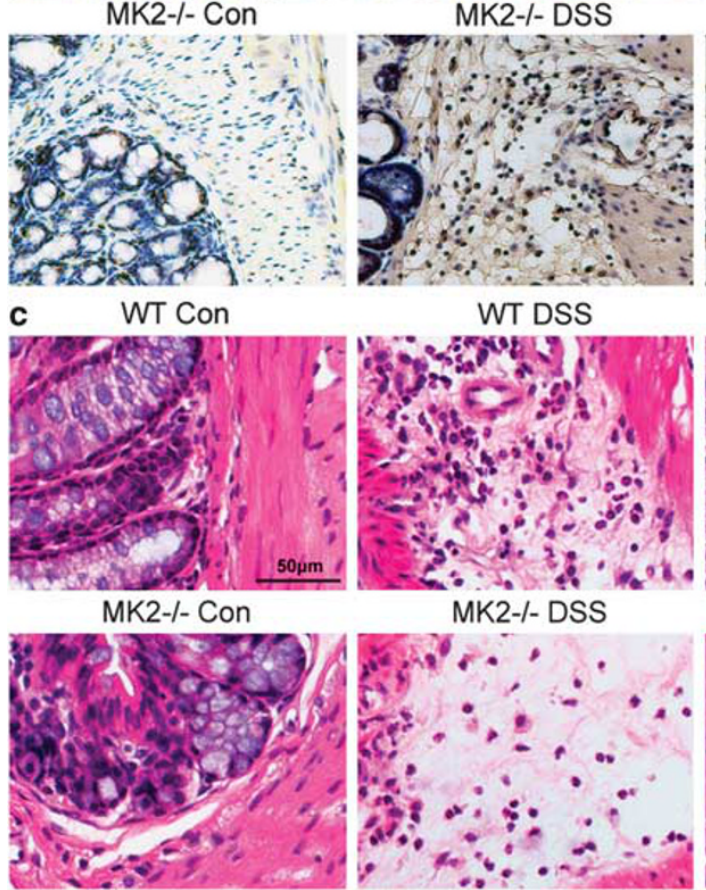

WT DSS

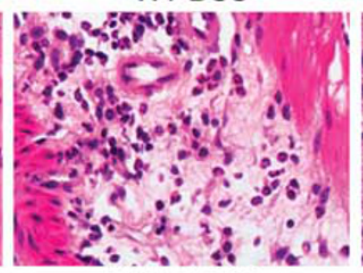
MK2-/- DSS
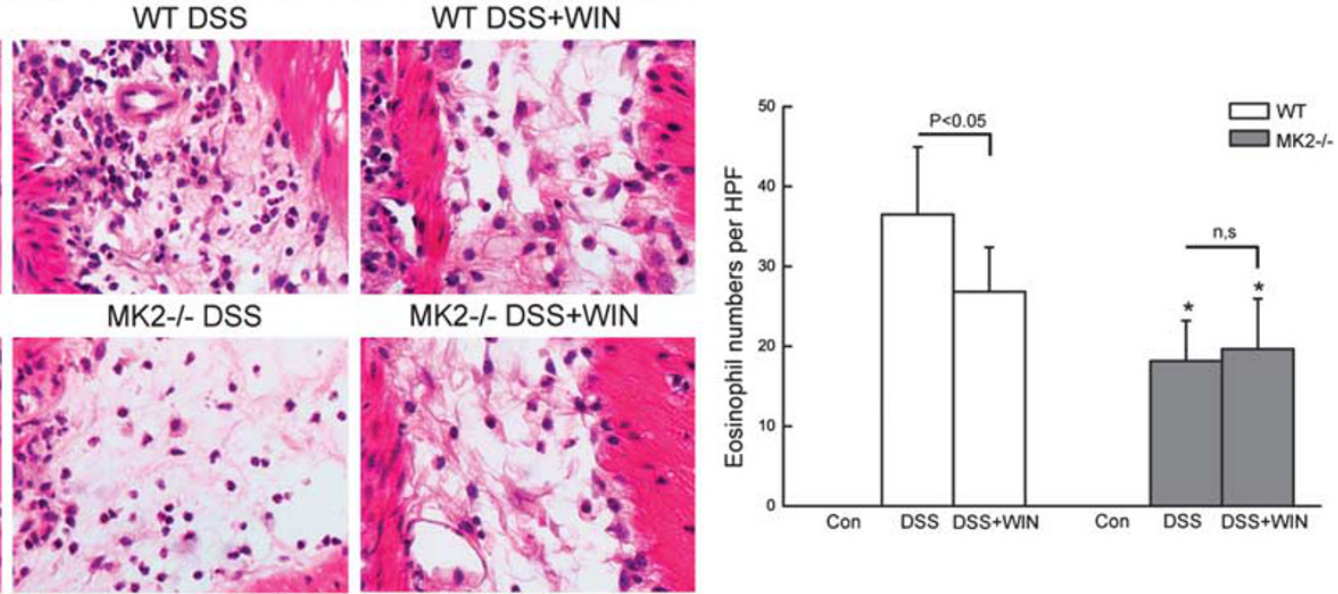

Figure 3 Inflammatory cell counting in colonic specimens of mice with dextran sodium sulfate (DSS)-induced colitis. Left panels show representative pictures (original magnification, $\times 400$ ) of macrophages (a) (stained in brown), neutrophils (b) (stained in brown), and eosinophils (c) (showing red cytoplasmic staining), and the bar graphs of the right panels present the corresponding data of cell numbers per high-power field (HPF) in colon tissue samples isolated from wild-type (WT) and Mk2 - / - mice that were either treated with DSS, DSS and WIN55, 212-2 (WIN55), WIN55 alone, or untreated. Data represent means \pm s.e. ( $n=3$ per group, one-way analysis of variance (ANOVA), Tukey's multiple comparison). ${ }^{*} P<0.05$ when compared with the values of wild-type mice in the identically treated groups. Con, control; Mk2, mitogen-activated protein kinase-activated protein kinase-2, also known as MAKAP kinase-2; n.s, nonsignificant.

homozygous deletion $(M k 2-/-)$ and WIN55, an agonist of $\mathrm{CB}$ receptors, on the local and systemic inflammatory response in mice with DSS-induced colitis taking advantage of the availability of $M k 2-I-$ mice and the mouse colitis model. Our results confirm that uptake of $4 \%$ DSS in drinking water for 7 consecutive days causes colitis with 
a

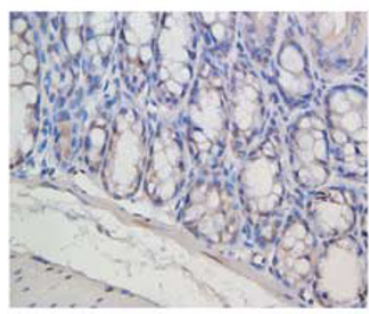

b

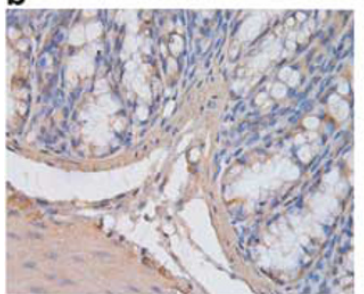

c

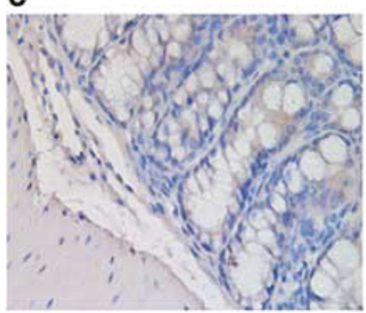

d

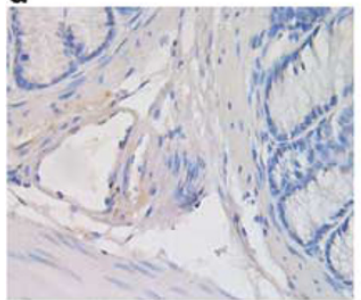

Con
Wild type p38

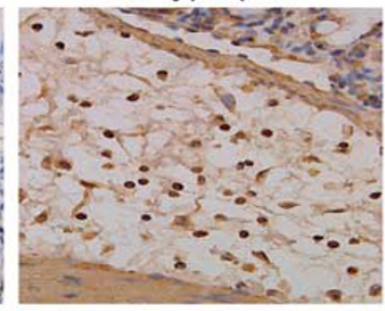

MK2-I- p38

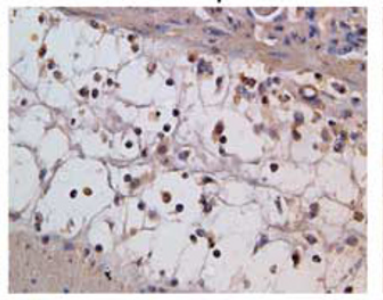

Wild type pp38

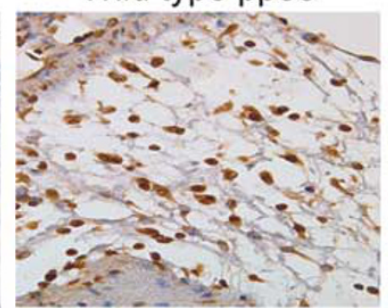

MK2-I- pp38

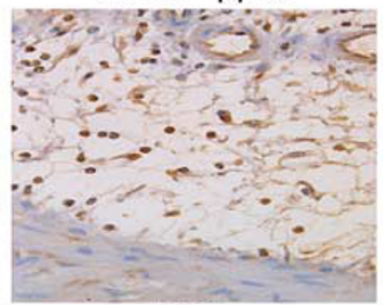

DSS
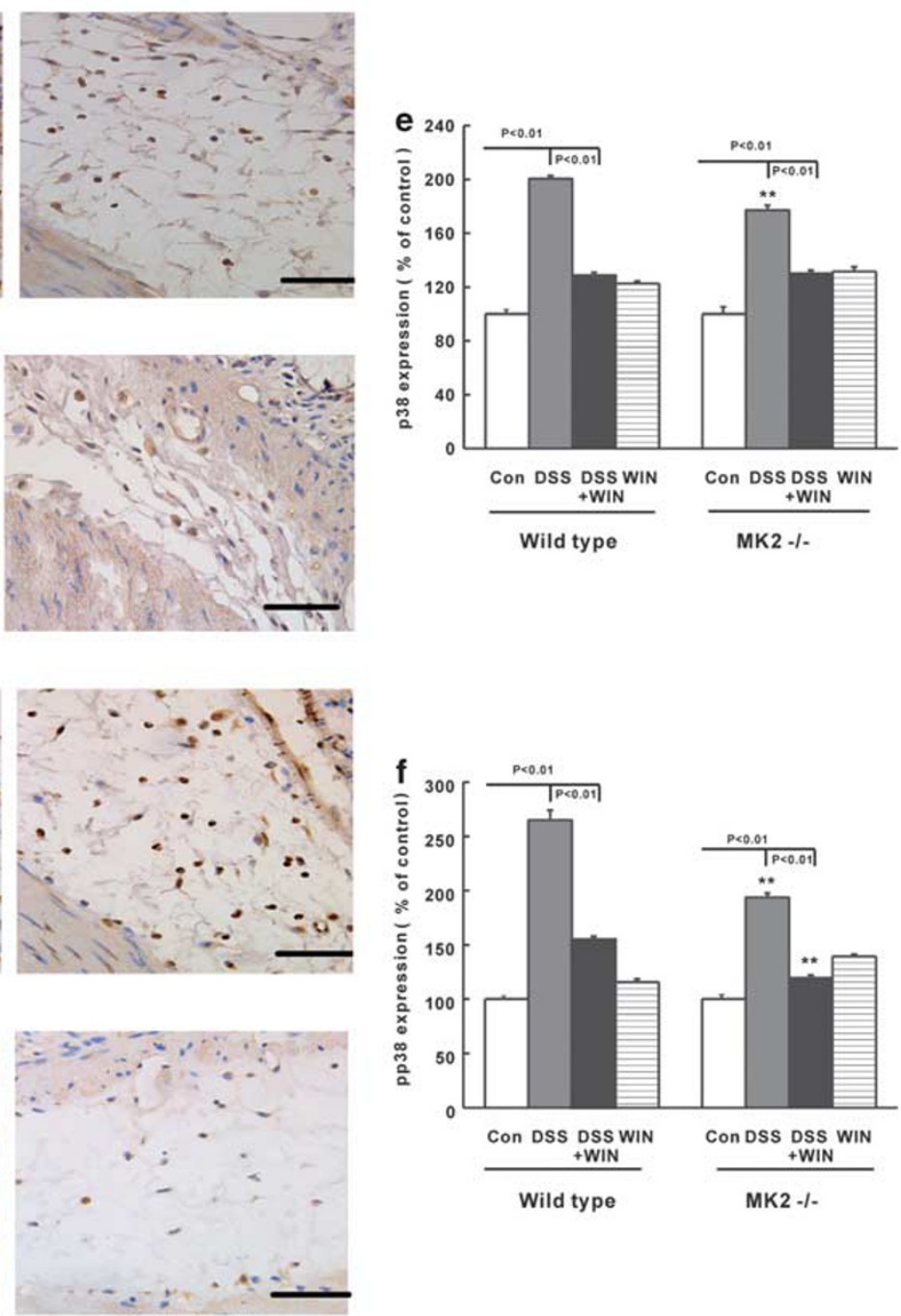

DSS+WIN

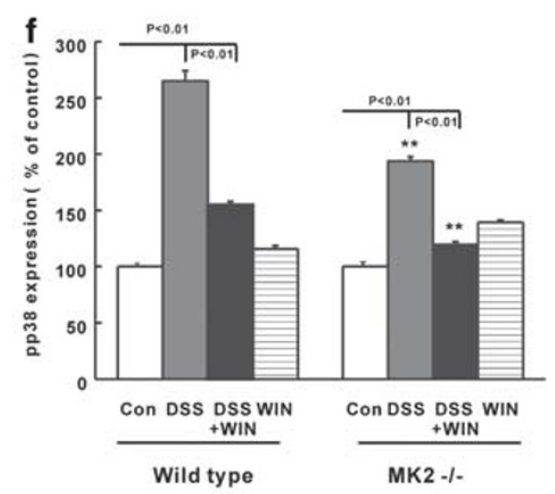

Figure 4 P38 MAPK expression in mouse colonic tissue. Representative pictures of mouse colonic tissue isolated from wild-type (a, c) or Mk2 - / mice (b, d), respectively, stained (in brown) with antibodies specific for p38 (a, b) or pp38 (c, d). Mice received either normal drinking water (control (Con)) or were treated with dextran sodium sulfate (DSS) or DSS and WIN55, 212-2 (WIN55). Scale bar $=50 \mu \mathrm{m}$. (e, f) Bar graphs representing the quantitative analyses of the immunohistochemical stainings (a-d) of Con (white bars), DSS (gray bars), DSS and WIN55 (black bars), as well as animals treated only with WIN55 (ruled bars) employing antibodies against p38 (e) or its phosphorylated form (p-p38) (f). Data represent means \pm s.e. ( $n=4$ per group) ${ }^{*} P<0.05,{ }^{*} P<0.01$, when compared with the values of wild-type mice in the identically treated groups. Mk2, mitogen-activated protein kinase-activated protein kinase-2, also known as MAKAP kinase-2.

typical manifestations: colonic epithelial damage and evident inflammatory responses paired with bloody stool and shortened colon owing to shrinkage, an indirect marker of inflammation, ${ }^{34}$ followed by body weight loss.

It is well known that cytokines have an important role in the pathogenesis of experimental colitis and human IBD. ${ }^{35,36}$ In our experiment, DSS was found as a stimulant that readily induced expression of inflammatory mediators in mice, including cytokines (TNF- $\alpha$, IL-6, and IL-10), chemokines (CINC-1 and MCP-1), and Cox-2, at mRNA level and/or protein level, and raise MPO activity in the lung tissue (a marker of neutrophil infiltration). Although inflammation is essential for protection against various pathogenic attacks in the primary stages of IBD, lasting and uncontrolled inflammatory responses, as the disease progresses, may lead to cytokine cascade effects resulting in the damage of intestinal tissues and even remote organs.

Inflammatory response is dependent on stimulation of signaling pathways within the cell. P38 MAPK pathway regulates inflammation through downstream proteins and kinases, affecting gene transcription directly and indirectly. ${ }^{37}$ Activated p38 MAPK increases the recruitment and activation of lymphocytes and neutrophils and delays apoptosis of these cells, ${ }^{9,38,39}$ which are the major source of perpetual production of inflammatory mediators. In the colon of mice with DSS-induced colitis, we found a high 

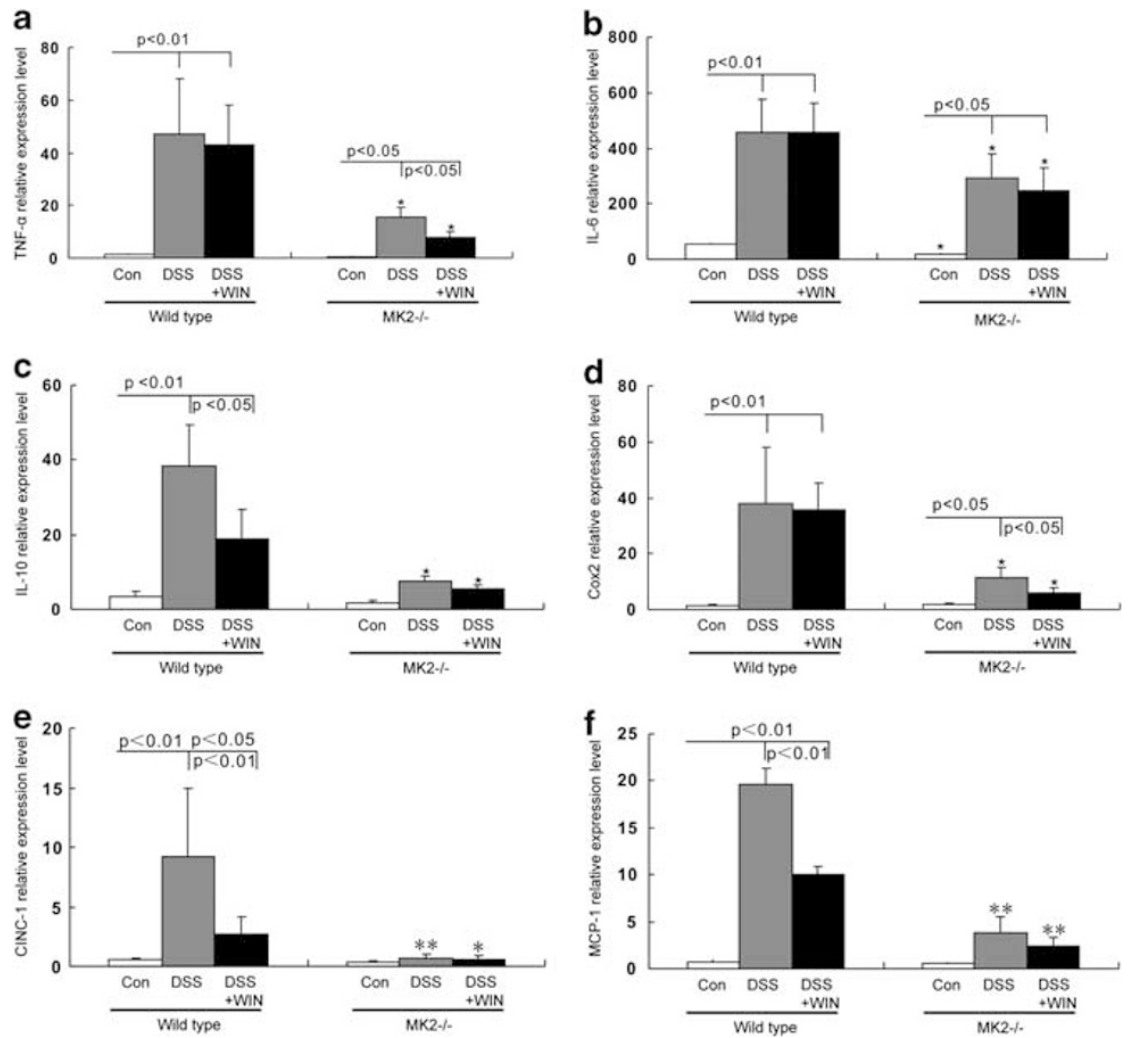

Figure 5 Cytokine and chemokine mRNA expression in mouse colonic tissues. Bar graphs representing the mRNA expression level of tumor necrosis factor (TNF) $\alpha$ (a), interleukin (IL)-6 (b), IL-10 (c), cyclooxygenase-2 (Cox-2) (d), cytokine-induced neutrophil chemoattractant-1 (CINC-1) (f), and monocyte chemoattractant protein-1 (MCP-1) (f) in colon tissue of wild-type or Mk2 - / - mice, respectively, of control (Con) animals (white bars), or animals treated with dextran sodium sulfate (DSS) (gray bars), or with DSS and WIN55, 212-2 (WIN55) (black bars). Values are presented as means \pm s.e. ( $n=5$ mice per group). ${ }^{*} P<0.05$ when compared with the values of wild-type mice in the identically treated groups. Mk2, mitogen-activated protein kinaseactivated protein kinase-2, also known as MAKAP kinase-2.

expression of both p38 MAPK and its phosphorylated form p-p38 in recruited inflammatory cells of the colonic submucosal plexus, together with the predicted effects: high expression and high levels of CINC-1/KC and MCP-1 and proinflammatory cytokines both in the local tissues and in the blood. Capable of recruiting monocytes, memory $\mathrm{T}$ cells, and dendritic cells to sites of tissue injury and infection, MCP-1 indirectly contributes to neutrophil recruitment to lungs, ${ }^{40-42}$ as shown by increased $\mathrm{MPO}$ activity in lung tissue samples. In contrast, CINC-1 is a functional analog of IL-8 concerning neutrophil recruitment and activation. ${ }^{42}$ Our results demonstrate the toxic effect of DSS on intestinal epithelium and mucosal barrier, causing a robust inflammatory response. Throughout the progress of inflammation, there is a constant recruitment of inflammatory cells, such as neutrophils and monocytes in the colon and lung tissues of mice with DSS-induced colitis. In addition, as CD4 $\mathrm{T}$ cells are important effectors of IBD, it will be of major interest to investigate their function in DSSinduced colitis in WT and Mk2-deficient mice.

Numerous reports have shown that the CB1 receptor is coupled to the activation of $\mathrm{p} 38 \mathrm{MAPK}$ in vitro and in vivo. ${ }^{43}$
Therefore, MAPK activation can be used as a screening assay to evaluate CB1 agonists. ${ }^{44}$ Moreover, CB1 agonists promote behavioral changes in rodents, including analgesia, hypomotility, hypothermia, and catalepsy. A tetrad test has been developed to monitor these behavioral changes in animals. Mk2, the direct substrate of $\mathrm{p} 38 \alpha$ and $\mathrm{p} 38 \beta$, is a multifunctional signaling protein in the progression of inflammation. ${ }^{45}$ By the targeted disruption of $M k 2$ gene in mice, a mouse strain with $M k 2-/$ - homozygous deletion has been generated earlier, and offered a useful tool for research in relevant fields. ${ }^{13,15}$ In this report, we presented fresh evidence that $M k 2$ deficiency attenuates the expression of TNF- $\alpha$, IL-6, IL-10, as well as CINC-1, MCP-1, and Cox-2 in mice with DSS-induced colitis at the transcriptional and/ or post-transcriptional level. Interestingly, $M k 2$ deficiency also reduced the DSS-induced enhancement of p38 and p-p38 expression, suggesting a positive feedback regulation between $\mathrm{Mk} 2$ and $\mathrm{p} 38$. Attenuating the inflammatory response induced by DSS, Mk2-I- mice manifested lower DAI, reduced inflammatory cell infiltration and histological score in colon, reduced MPO activity in lungs, and decreased levels of inflammatory mediators in plasma 

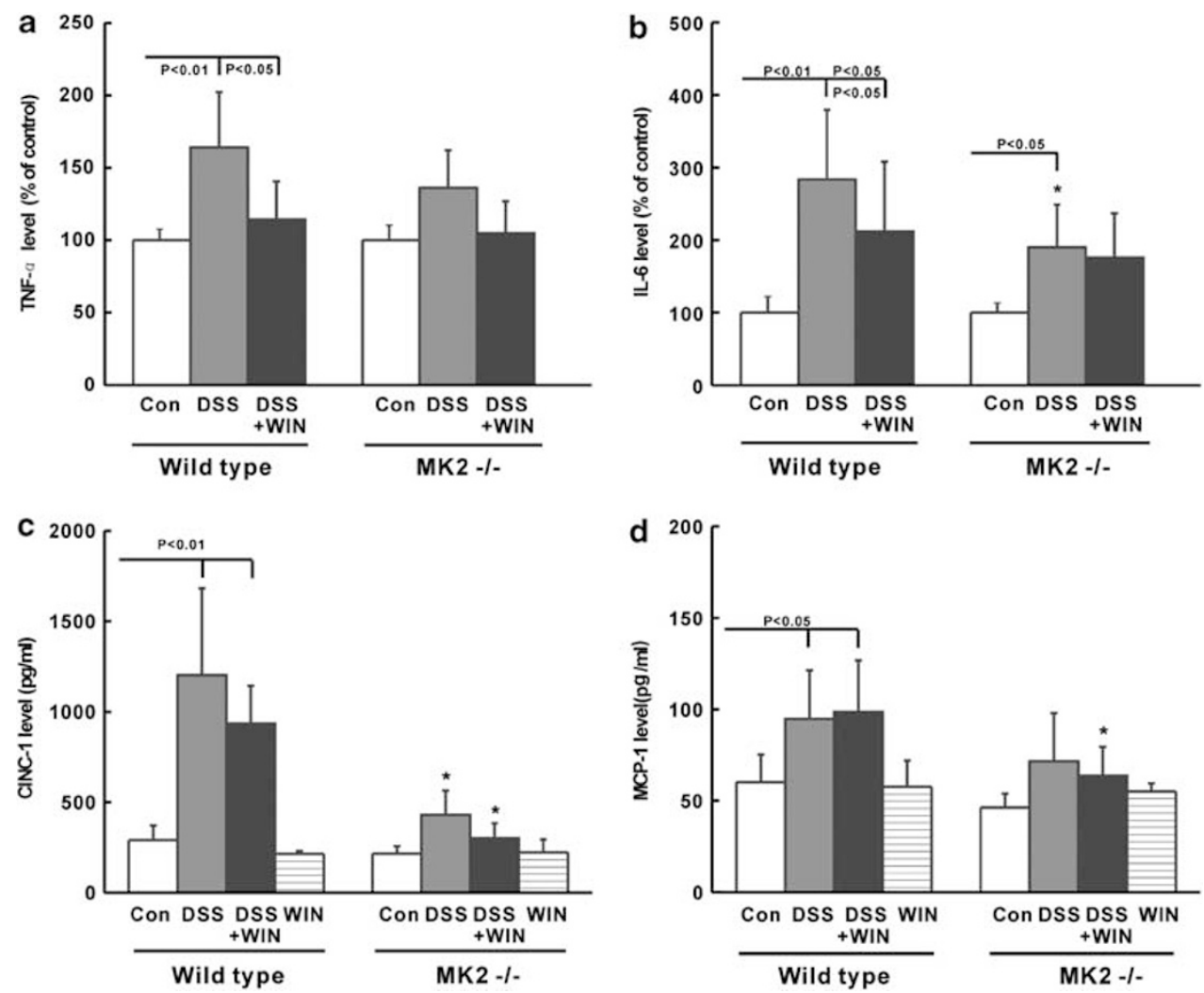

Figure 6 Plasma level of proinflammatory cytokines and chemokines. The levels of tumor necrosis factor (TNF)- $\alpha$ (a), interleukin (IL)-6 (b), cytokineinduced neutrophil chemoattractant-1 (CINC-1) (c), and monocyte chemoattractant protein-1 (MCP-1) (d) were determined by enzyme-linked immunosorbent assay (ELISA). The treatment in every group was-Con: control group in which mice drank water; dextran sodium sulfate (DSS): the group in which mice drank 4\% DSS solution; DSS + WIN: the group in which mice drank 4\% DSS solution and received WIN55, 212-2 (WIN55) intraperitoneally (i.p.); WIN: the group in which mice drank water and received WIN55 i.p. Data are expressed as means \pm s.e. ( $n=6$ mice per group, one-way analysis of variance (ANOVA), Tukey's multiple comparison). ${ }^{*} P<0.05$ when compared with the values of wild-type mice in the identically treated groups. Mk2, mitogen-activated protein kinase-activated protein kinase-2, also known as MAKAP kinase- 2 .

and in intestinal tissues compared with those of WT mice, further confirming the role of $\mathrm{p} 38 / \mathrm{Mk} 2$ in the bowel inflammatory disease.

With the progress of understanding IBD pathogenesis, new therapeutics, for example, leukocytapheresis and anti-TNF- $\alpha$ antibody, together with some drugs aiming to attenuate local inflammation in the mucosa (corticosteroids, 5-aminosalicylate compounds, and immune-suppressing agents), have been proven effective for IBD patients. ${ }^{2}$ Nevertheless, clinical practice uncompromisingly requires more optimal medical therapies. In recent years, multiple lines of convincing evidences demonstrate that CB1 and CB2 receptors' agonists promote the release of endocannabinoids and exert autoprotective effects in bowl inflammatory disease. ${ }^{46-48} \mathrm{CB}$ receptors are G-protein-coupled CB1 receptor is predominantly expressed in nerve tissues, whereas CB2 receptor is mainly expressed in immune cells and mediates cytokine and chemokine release. As a non-selective $\mathrm{CB}$ receptor agonist, WIN55 has emerged as a promising agent with remarkable anti-inflammatory properties. The study of Sheng et al ${ }^{49}$ demonstrated that WIN55 suppresses the production of inflammatory mediators such as nitric oxide (NO) and TNF- $\alpha$. In addition, TNF- $\alpha$ induced IL- 8 release and NF- $\kappa \mathrm{B}$ activation drastically decreased upon WIN55 administration..$^{50}$ In this study, we have scrutinized the antiinflammatory effect of WIN55 in DSS-induced mouse colitis and evidenced that WIN55 counteracts the DSS-induced enhancement of p38 and p-p38 expression, especially the expression of p-p38 in Mk2-deficient mice, and furthermore suppresses the expression of proinflammatory cytokines (TNF- $\alpha$ and IL-6) and chemokines (CINC-1 and MCP-1, Cox-2). The histological and DAI scores, as integrated indexes, are affected by many factors, in addition to TNF$\alpha$, IL-6, and Cox-2. These cytokines and Cox-2 have important roles in the pathogenesis and pathological changes of colitis, and the results showed that both DAI and histological scores were significantly reduced by WIN55 in WT and $M k 2-/-$ mice, but more prominent in $M k 2-I-$ mice. IL-12, IL-23, and IL-17 are further important factors involved in the pathogenesis of IBD. Investigating their transcript levels in our experimental setup, we found the same tendencies in gene expression as observed 


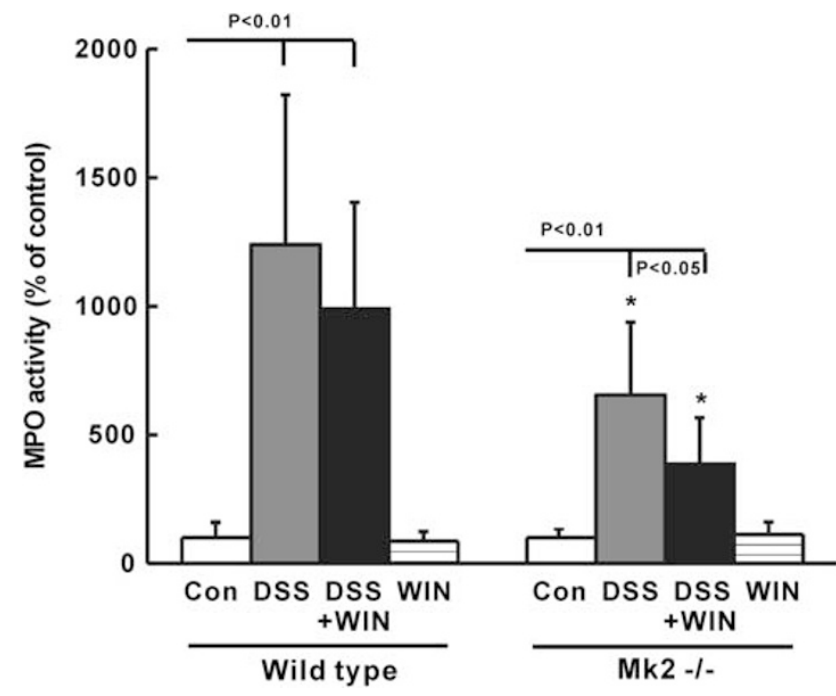

Figure 7 Assay of myeloperoxidase (MPO) activity in mouse lung tissues. Bar graphs representing MPO activity in lung tissue of wild-type and Mk2 - / - mice. The treatment in every group was-Con: control group in which mice drank water; dextran sodium sulfate (DSS) the group in which mice drank $4 \%$ DSS solution; DSS + WIN: the group in which mice drank 4\% DSS solution and received WIN55, 212-2 (WIN55)

intraperitoneally (i.p.); WIN: the group in which mice drank water and received WIN55 i.p. Data represent means \pm s.e. ( $n=8$ per group; oneway analysis of variance (ANOVA), Tukey's multiple comparison). ${ }^{*} P<0.05$ when compared with the values of wild-type mice in the identically treated groups. Mk2, mitogen-activated protein kinase-activated protein kinase-2, also known as MAKAP kinase-2.

for TNF- $\alpha$ and IL-6 in the different treated groups (data not shown). These findings highlight that Mk2 deficiency and CB receptor activation forward a synergistic protection against the local and systemic pathological changes in the DSSinduced mouse colitis model.

In this study, we found that deletion of $M k 2$ resulted in decreased levels of phosphorylated p38 MAPK in the colon of mice with DSS-induced colitis. It is well known that Mk2 is one of several kinases directly regulated by p38 MAPK. Mk2 is directly activated via p38 MAPK phosphorylation, then binds to p38 and stabilizes p38 by complex formation, and finally contributes to stress responses. Hence, in the absence of $\mathrm{Mk} 2 / 3$, reduced levels of $\mathrm{p} 38$ protein and activity have been detected in some organ tissues, such as heart and spleen, by Ronkina et all ${ }^{12}$ and Kotlyarov et $a l,{ }^{13}$ and now detected in colon tissue by us. However, reduced levels of pp38 in Mk2 - I - mice might also be the result of reduced TNF- $\alpha$ level accounting for reduced stimulation of p38 MAPK activation. The effect of WIN55 appears to be more protective and effective at changing p38 MAPK phosphorylation than that of $M k 2$ deficiency, but in Mk2 - I - mice the effect of WIN55 on inhibiting p38 MAPK phosphorylation is more significant. These results provide some fresh and direct evidences through a different avenue; however, further investigations are required to elucidate the linkage and cross-talking between the p38 MAPK signaling pathway and the CB system.

In this study, by using a DSS-induced mouse colitis model, we found the levels of proinflammatory cytokines, including $\mathrm{TNF}-\alpha$, in colon and in blood, as well as the inflammatory reaction in colon reduced in the Mk2-I- mice. Although Mk2 absence showed a modest impact on the local inflammatory reaction, the analysis proved statistical differences in DAI, colon length, and histological score between WT and Mk2 - I - mice. Contrary to our results and even to the presumed requirements for the activation of proinflammatory programs, Kontoyiannis et $a l^{51}$ found, by using a TNF- $\alpha$ overexpression-mediated mouse IBD model, the disease exacerbated in mice deficient for $M k 2$, correlated with decreased apoptosis of mononuclear cells in the lamina propria. The differences between our results and theirs could be explained by different methodology, moreover, by the different pathogenesis of both models.

In summary, we demonstrate that the local and systemic pathological changes in DSS-induced mouse colitis are effectively attenuated by WIN55 administration and/or by $M k 2$ deficiency displaying that both the $\mathrm{CB}$ system and p38/Mk2 signaling pathway are involved in the regulation of inflammation, but with different functions: $\mathrm{CB}$ system has an anti-inflammatory role, whereas $\mathrm{p} 38 / \mathrm{Mk} 2$ participates in the signal transduction of inflammatory processes. Furthermore, we have confirmed that the $\mathrm{CB}$ receptor agonist WIN55 protects against DSS-induced mouse colitis and that this effect is potentiated and enforced by the inhibition of the p38/Mk2 pathway. Hence, $M k 2$ might serve as a potential drug target for IBD treatment in view of the fact that $M k 2-I-$ mice acquire a much stronger resistance to DSS-induced inflammatory response in mouse experimental colitis.

\section{ACKNOWLEDGEMENTS}

We thank Ms MP Wu and Professor BG Song for their kind help in the qRTPCR technical issues and pathological evaluation, respectively. We also thank Dr A Kotlyarov and Professor Dr M Gaestel for providing the group with the Mk2 - / - mice. This work was supported by grants from the National Science Foundation of China (Nos. 30971168 and 81270477 to Dr YY Li) and the Deutsche Forschungsgemeinschaft of Germany (DFG; MS 645/6-1 and YU 132/1-2 to Dr M Storr and Dr B Yuece).

Author contributions: YY Li, B Yuece, M Storr and C Schaefer designed the protocols of the research and supported the research; $Y Y L i$ and B Yuece performed, and XH Lin, MH Cao, S LV, CJ Chen, S Ochs, A Sibaev, and E Deindl helped to perform the experiments, including the supplemental experiments; YY Li, XH Lin, and S Lv analyzed the data; and YY Li and B Yuece wrote and completed the manuscript.

\section{DISCLOSURE/CONFLICT OF INTEREST}

The authors declare no conflict of interest.

1. Baumgart DC, Carding SR. Inflammatory bowel disease: cause and immunobiology. Lancet 2007;369:1627-1640.

2. Rijnierse A, Nijkamp FP, Kraneveld AD. Mast cells and nerves tickle in the tummy: implications for inflammatory bowel disease and irritable bowel syndrome. Pharmacol Ther 2007;116:207-235. 
3. Choi SY, Hur SJ, An CS, et al. Anti-inflammatory effects of Inonotus obliquus in colitis induced by dextran sodium sulfate. J Biomed Biotechnol 2010:2010:943516.

4. Chang L, Karin M. Mammalian MAP kinase signalling cascades. Nature 2001;410:37-40.

5. Hollenbach $\mathrm{E}$, Vieth $\mathrm{M}$, Roessner $\mathrm{A}$, et al. Inhibition of RICK/nuclear factor-kappaB and p38 signaling attenuates the inflammatory response in a murine model of Crohn disease. J Biol Chem 2005;280:14981-14988.

6. Hommes $D$, van den Blink $B$, Plasse $T$, et al. Inhibition of stressactivated MAP kinases induces clinical improvement in moderate to severe Crohn's disease. Gastroenterology 2002;122:7-14.

7. Scaldaferri F, Correale C, Gasbarrini A, et al. Molecular signaling blockade as a new approach to inhibit leukocyte-endothelial interactions for inflammatory bowel disease treatment. Cell Adhes Migr 2009;3:296-299.

8. Fiocchi C. Intestinal inflammation: a complex interplay of immune and nonimmune cell interactions. Am J Physiol 1997:273:G769-G775.

9. Danese $S$, Semeraro $S$, Marini $M$, et al. Adhesion molecules in inflammatory bowel disease: therapeutic implications for gut inflammation. Dig Liver Dis 2005;37:811-818.

10. Hollenbach $E$, Neumann $M$, Vieth $M$, et al. Inhibition of p38 MAP kinase- and RICK/NF-kappaB-signaling suppresses inflammatory bowel disease. FASEB J 2004;18:1550-1552.

11. Kotlyarov A, Neininger A, Schubert C, et al. MAPKAP kinase 2 is essential for LPS-induced TNF-alpha biosynthesis. Nat Cell Biol 1999;1:94-97.

12. Ronkina N, Kotlyarov A, Dittrich-Breiholz O, et al. The mitogenactivated protein kinase (MAPK)-activated protein kinases MK2 and MK3 cooperate in stimulation of tumor necrosis factor biosynthesis and stabilization of p38 MAPK. Mol Cell Biol 2007:27:170-181.

13. Kotlyarov A, Yannoni Y, Fritz S, et al. Distinct cellular functions of MK2. Mol Cell Biol 2002;22:4827-4835.

14. Li YY, Ochs S, Gao ZR, et al. Regulation of HSP60 and the role of MK2 in a new model of severe experimental pancreatitis. Am J Physiol Gastrointest Liver Physiol 2009;297:G981-G989.

15. Tietz AB, Malo A, Diebold J, et al. Gene deletion of MK2 inhibits TNFalpha and IL-6 and protects against cerulein-induced pancreatitis. Am J Physiol Gastrointest Liver Physiol 2006;290:G1298-G1306.

16. Thomas T, Timmer M, Cesnulevicius $\mathrm{K}$, et al. MAPKAP kinase 2deficiency prevents neurons from cell death by reducing neuroinflammation-relevance in a mouse model of Parkinson's disease. J Neurochem 2008;105:2039-2052.

17. Martin F, Matthias P. Factors associated with the subject's ability to quantify their lumbar flexion demands at work. Int J Environ Health Res 2006;16:69-79.

18. Di Marzo V. Targeting the endocannabinoid system: to enhance or reduce? Nat Rev Drug Discov 2008;7:438-455.

19. $\mathrm{Li} \mathrm{YY}, \mathrm{Li} \mathrm{YN}, \mathrm{Ni} J \mathrm{~B}$, et al. Involvement of cannabinoid-1 and cannabinoid-2 receptors in septic ileus. Neurogastroenterol Motil 2010;22:350-e388.

20. Matsuda LA, Lolait SJ, Brownstein MJ, et al. Structure of a cannabinoid receptor and functional expression of the cloned cDNA. Nature 1990;346:561-564.

21. Pertwee RG. Cannabinoids and the gastrointestinal tract. Gut 2001;48:859-867.

22. Massa F, Marsicano $\mathrm{G}$, Hermann $\mathrm{H}$, et al. The endogenous cannabinoid system protects against colonic inflammation. J Clin Invest 2004:113:1202-1209.

23. Buckley NE. The peripheral cannabinoid receptor knockout mice: an update. Br J Pharmacol 2008;153:309-318.

24. Wright KL, Duncan M, Sharkey KA. Cannabinoid CB2 receptors in the gastrointestinal tract: a regulatory system in states of inflammation. $\mathrm{Br}$ J Pharmacol 2008;153:263-270.

25. Izzo AA, Mascolo N, Capasso F. The gastrointestinal pharmacology of cannabinoids. Curr Opin Pharmacol 2001:1:597-603.

26. Storr MA, Yüce $B$, Andrews $C N$, et al. The role of the endocannabinoid system in the pathophysiology and treatment of irritable bowel syndrome. Neurogastroenterol Motil 2008;20:857-868.

27. Fitzpatrick LR, Deml L, Hofmann C, et al. 4SC-101, a novel immunosuppressive drug, inhibits IL-17 and attenuates colitis in two murine models of inflammatory bowel disease. Inflamm Bowel Dis 2010;16:1763-1777.
28. Cooper HS, Murthy SN, Shah RS, et al. Clinicopathologic study of dextran sulfate sodium experimental murine colitis. Lab Invest 1993:69:238-249.

29. Hartmann G, Bidlingmaier C, Siegmund B, et al. Specific type IV phosphodiesterase inhibitor rolipram mitigates experimental colitis in mice. J Pharmacol Exp Ther 2000;292:22-30.

30. Siegmund $\mathrm{B}$, Rieder $\mathrm{F}$, Albrich $\mathrm{S}$, et al. Adenosine kinase inhibitor GP515 improves experimental colitis in mice. J Pharmacol Exp Ther 2001;296:99-105.

31. Chomczynski P, Sacchi N. Single-step method of RNA isolation by acid guanidinium thiocyanate-phenol-chloroform extraction. Anal Biochem 1987:162:156-159.

32. Tolstanova G, Deng XM, French SW, et al. Early endothelial damage and increased colonic vascular permeability in the development of experimental ulcerative colitis in rats and mice. Lab Invest 2012;92:9-21.

33. Whittem CG, Williams AD, Williams CS. Murine colitis modeling using dextran sulfate sodium (DSS). J Vis Exp 2010;35:1652.

34. Diaz-Granados N, Howe K, Lu J, et al. Dextran sulfate sodium-induced colonic histopathology, but not altered epithelial ion transport, is reduced by inhibition of phosphodiesterase activity. Am J Pathol 2000;156:2169-2177.

35. Hanauer SB. Inflammatory bowel disease: epidemiology, pathogenesis, and therapeutic opportunities. Inflamm Bowel Dis 2006;12(Suppl 1):S3-S9.

36. Van Assche $G$, Vermeire $S$, Rutgeerts P. Focus on mechanisms of inflammation in inflammatory bowel disease sites of inhibition: current and future therapies. Gastroenterol Clin N Am 2006:35:743-756.

37. Broom OJ, Widjaya B, Troelsen J, et al. Mitogen activated protein kinases: a role in inflammatory bowel disease? Clin Exp Immunol 2009;158:272-280

38. Scaldaferri $F$, Sans $M$, Vetrano $S$, et al. The role of MAPK in governing lymphocyte adhesion to and migration across the microvasculature in inflammatory bowel disease. Eur J Immunol 2009;39:290-300.

39. Saklatvala J, Dean J, Clark A. Control of the expression of inflammatory response genes. Biochem Soc Symp 2003;70:95-106.

40. Watanabe $\mathrm{T}$, Higuchi $\mathrm{K}$, Hamaguchi M, et al. Monocyte chemotactic protein-1 regulates leukocyte recruitment during gastric ulcer recurrence induced by tumor necrosis factor-alpha. Am J Physio Gastrointest Liver Physiol 2004;287:G919-G928.

41. Rosenthal LA, Amineva SP, Szakaly RJ, et al. A rat model of picornavirus-induced airway infection and inflammation. Virol J 2009;6:122.

42. Kinoshita K, Horiguchi K, Fujisawa M, et al. Possible involvement of muscularis resident macrophages in impairment of interstitial cells of Cajal and myenteric nerve systems in rat models of TNBS-induced colitis. Histochem Cell Biol 2007:127:41-53.

43. Long JZ, Li W, Booker L, et al. Selective blockade of 2arachidonoylglycerol hydrolysis produces cannabinoid behavioral effects. Nat Chem Biol 2009;5:37-44.

44. Wit RD, Boonstra J, Verkleij AJ, et al. Large scale screening assay for the phosphorylation of mitogen-activated protein kinase in cells. J Biomol Screen 1998;3:277-278.

45. Feng YJ, Li YY. The role of p38MAPK in the pathogenesis of inflammatory bowel disease. J Dig Dis 2011;12:327-332.

46. Croci $\mathrm{T}$, Landi $\mathrm{M}$, Galzin $\mathrm{AM}$, et al. Role of cannabinoid $\mathrm{CB}_{1}$ receptors and tumor necrosis factor- $\alpha$ in the gut and systemic anti-inflammatory activity of SR 141716 (Rimonabant) in rodents. Br J Pharmacol 2003;145:115-122

47. Kimball ES, Schneider $\mathrm{CR}$, Wallace $\mathrm{NH}$, et al. Agonists of cannabinoid receptor 1 and 2 inhibit experimental colitis induced by oil of mustard and by dextran sulfate sodium. Am J Physiol 2006;291:G364-G371.

48. Hanson M, Bueno L, Fioramonti J. Involvement of cannabinoid receptors in inflammatory hypersensitivity to colonic distension in rats. Neurogastroenterol Motil 2006;18:949-956.

49. Sheng WS, Hu S, Min X, et al. Synthetic cannabinoid WIN55, 212-2 inhibits generation of inflammatory mediators by IL-1beta-stimulated human astrocytes. Glia 2005;49:211-219.

50. Izzo AA, Camilleri M. Emerging role of cannabinoids in gastrointestinal and liver diseases: basic and clinical aspects. Gut 2008;57:1140-1155.

51. Kontoyiannis D, Boulougouris G, Manoloukos M, et al. Genetic dissection of the cellular pathways and signaling mechanisms in modeled tumor necrosis factor-induced Crohn's-like inflammatory bowel disease. J Exp Med 2002;196:1563-1574. 